\title{
Impact of Elicitation by Methyl Jasmonate and Ethephon on Cotton (Gossypium Hirsutum L.) Protection Against Fusarium Oxysporum F. Sp. Vasinfectum
}

N'cho Achi Laurent ${ }^{*}$, Yapo Sopie Edwige Salomé ${ }^{2}$ Amari Ler-N’Ogn Dadé Georges Elisée ${ }^{3}$, Kouakou Tanoh Hilaire ${ }^{1}$

${ }^{1}$ UFR SN, Laboratoire de Biologie et Amélioration de Productions Végétales, Université Nangui Abrogoua, 02 BP 801 Abidjan 02, Côte d'Ivoire. laurentncho6@yahoo.fr, tanohilaire@yahoo.fr

²UFR Agroforesterie, Université Lorougnon Guédé. BP 150 Daloa, Côte d'Ivoire

${ }^{3}$ UFR Biosciences, Laboratoire de Physiologie Végétale, Université Félix Houphouët-Boigny. 22 BP 582 Abidjan 22, Côte d'Ivoire

amariler@yahoo.fr, sopiedeyapo@yahoo.fr

\begin{abstract}
The objective of the study was to evaluate the effect of methyl jasmonate and ethephon on cotton against Fusarium wilt. As well, cotton plants were treated in the field by methyl jasmonate (MeJA), ethephon (ETH) and the association of methyl jasmonate and ethephon (MeJA + ETH) and inoculated by Fusarium oxysporum f. sp. Vasinfectum (FOV). The incidence of the disease caused by FOV was evaluated every 10 days up to the 150th day after inoculation. The protection afforded to cotton following treatment by stimulators was assessed by determining the mortality rate of plants treated and inoculated FOV compared with untreated and inoculated controls. The degree of protection of cotton from Fusarium wilt was also determined through growth parameters, foliar pigment content (Chlorophylls and carotenoids) and an evaluation of the rate of lines. The results showed better protection of the cotton plants treated by the stimulators and inoculated by FOV through an increase in the number of healthy leaves, stem height, and stem diameter. This protection was also confirmed by an increase in photosynthetic activity of plants and a reinforcement of cell walls. The combination of these two molecules (MeJA + ETH) was better to induce this resistance against FOV compared to each of the two taken separately. The use of natural defence stimulators (SDN) is therefore an effective means of protecting cotton from FOV. Their application in the agricultural environment could contribute to the development of a well-reasoned, sustainable agriculture that is more respectful of the environment and human health.
\end{abstract}

Indexing terms/Keywords: cotton, methyl jasmonate, ethephon, natural defence stimulator, Fusarium oxysporum f. sp. vasinfectum

Subject Classification: Plant Physiology and Physiopathology

\section{Introduction}

Cotton is a tropical plant belonging to the genus Gossypium, of which four species are currently cultivated. G. hirsutum is the most cultivated species, accounting for almost $95 \%$ of world cotton production (Munro, 1994). African cotton-producing countries account for only $8 \%$ of world production (Estur, 2005). Cotton plays important, economic and social role in Africa. Cotton represents a considerable economic and social importance in Africa. For example, it constitutes 7 \% of agricultural exports in Côte d'Ivoire and contributes to $1.7 \%$ of the annual gross domestic product. Thus, cotton is the fourth most important export product after cocoa, rubber and cashew and generates about 100 billion CFA franc currency in Côte d'Ivoire (Coulibaly, 2014). It provides substantial income for this purpose to the peasant masses in the central and northern parts of the country which are the main cotton regions. However, cotton is threatened by pests and various diseases that reduce the production and quality of fibres and seeds (Vaissayre, 1994). Of all the diseases of fungal origin, fusarium wilt caused by FOV seems to be the most formidable. It invades the interior of the plant and blocks the vessels where 
the sap circulates, which causes a generalized fanaison of the plant starting with the aerial parts. The attack is more intense when some nematodes such as Meloidogyne incognita are abundant in the soil (Delattre, 1973). The fungus can develop actively in the soil and persist for many years, even in the absence of the host plant. Fusarium wilt is one of the main causes of production loss in cotton cultivation. Thus, without chemical phytosanitary protection, there is no room today for profitable cotton production. Unfortunately, the use of pesticides, including fungicides, is increasingly on the spot for toxicity and environmental pollution issues (Faurie et al., 2013).

In this context, it appears necessary to look for more effective alternatives for the development of sustainable agriculture. One is to give plants the means to defend themselves, or to strengthen their own defences, rather than to directly combat the aggressor (Amari et al., 2014; Konan et al., 2014). In this category are the stimulators of the natural defenses (SDN) of the plants. Indeed, plants can most often naturally resist their aggressors through natural molecules called natural defence stimulators (Amari, 2012). SDN are effective at very low doses, inactive on pathogens as acting on the plant (Lyon et al., 1995). They are completely biodegradable and have a generally interesting eco-toxicologic profile. So they are very environmentally friendly molecules. Among which are methyl jasmonate and ethylene. The objective of this work is to evaluate the effectiveness of natural defence stimulators in the defence of cotton. Specifically, it aims was to evaluate the impact of methyl jasmonate and ethephon on cotton against Fusarium wilt caused by FOV.

\section{MATERIALS AND METHODS}

\section{Plant material}

The plant material consists of cotton seed (Gossypium hirsutum L.) from cultivar Y764G3, originating in Côte d'Ivoire (West Africa). It is an improved cultivar, resulting from the cross between local lines and introduced lines (Hau, 1988). The seeds were provided by the Ivorian Textile Development Company.

\section{Fungal material}

The fungal material consists of a strain of Fusarium oxysporum F. Sp. Vasinfectum (FOV). It was provided by the laboratory of plant pathology of the Higher School of Agronomy (ESA) This part should contain sufficient detail that would enable all procedures to be repeated. It can be divided into subsections if several methods are described. of the Polytechnic Institute Houphouët Boigny (INPHB) in Yamoussoukro in test tubes containing the PDA medium.

\section{Chemicals}

All chemicals used were at least analytical grade. Gallic acid, ethanol, methanol, sodium carbonate, triton X-100 and Folin-Ciocalteu reagent were purchased from Sigma-Aldrich (Natick, MA, USA). Methyl jasmonate (MeJA) and ethephon (ETH) produced by Aldrich (Natick, MA, USA).

\section{Site study}

This experiment was carried out in the field on the experimental plot of the Nangui Abrogoua University (UNA) in Abidjan (southern Côte d'Ivoire). The geographical coordinates of this site are: $5^{\circ} 17^{\prime}$ and $5^{\circ} 31^{\prime}$ North latitude between $3^{\circ} 45^{\prime}$ and $4^{\circ} 22^{\prime}$ West longitude (Koffi et al., 2009). The forest relic of this university contains numerous plant species such as Chrysophyllum albidum G. Don (Sapotaceae), Synsepalum afzelii (Engl.) T.D. Penn. (Sapotaceae), Palisota hirsute (Thunb.) K. Schum. (Commelinaceae). The soil is derived from sedimentary formations of the ferralitic type (Perraud, 1971). These sedimentary formations have a clay-sandy texture that is favorable to cotton growing. The mean annual rainfall and temperature are $1642 \mathrm{~mm}$ and $27.16^{\circ} \mathrm{C}$ (SODEXAM, 2017).

\section{Implementation of experimental design}


The experimental device used consists of four plots, separated by $100 \mathrm{~m}$ from each other. Each plot consists of three ridges $3 \mathrm{~m}$ long and $1 \mathrm{~m}$ wide. On each ridge, the pockets are separated by $30 \mathrm{~cm}$ and $20 \mathrm{~cm}$ from those of another ridge.

\section{Sowing seeds and obtaining cotton vivoplants}

The seeds were sown on the ridges at the rate of three seeds per pouch at $5 \mathrm{~cm}$ depth. At emergence, the plants were demigrated. Each ridge contains a row of 10 cotton plants, thus 30 cotton plants per basic plot. Plant growth was monitored for two months (size and number of leaves).

\section{Preparation and application of stimulators}

Methyl jasmonate (MeJA) was prepared at the optimum concentration of $5 \mathrm{mM}$ and ethephon (ETH) at $5 \mathrm{~g} / \mathrm{L}$ (Konan et al., 2015). The two stimulators were previously dissolved in $80 \%$ ethanol in the presence of $0.5 \mathrm{~mL}$ of $1 \%$ Triton X-100, and then supplemented with distilled water. About $500 \mathrm{~mL}$ of each stimulator solution was prepared. A second preparation consisting of an equal volume mixture of the two stimulators (MeJA+ETH) was performed. In every elementary plot of land, 10 plants were handled with three repetitions, that is all in all 30 handled plants of the cotton plant. During a treatment, plastic bags were used to separate the treated plants from the others, in order to avoid their contact with the solution. The treatment was carried out by spraying and each plant received $50 \mathrm{~mL}$ of solution. The control plants were sprayed with distilled water containing $1 \%$ Triton $\mathrm{X}-100$.

\section{Fungus culture}

\section{Transplanting and purifying FOV}

The transplantation of the strain FOV was carried out according to the method described by Vakili (1968). Thus, agar fragments of about $0.5 \mathrm{~cm}$ in diameter containing the fungus were collected and then put into test tubes. They were then transferred to the hood in petri dishes containing the $8 \%$ PDA medium and sterilized in autoclave at $120^{\circ} \mathrm{C}$ for $30 \mathrm{~min}$. The petri dishes thus sown were incubated for 14 days in a culture room at a temperature of $25^{\circ} \mathrm{C}$ with a 12 -h photoperiod.

\section{Pathogenicity of Fusarium oxysporum f. sp. vasinfectum}

The purpose of this pathogenicity test was to confirm the special form "vasinfectum" of our isolate of Fusarium oxysporum. The aggression of its specific host (the cotton) is manifested by the appearance of the external symptoms: yellowing of the leaves, convexity of the limb (epinasty), yellowing of the ribs beginning either by the circumference of the ribs. Yellowing and necrosis progress between the ribs and, at the end of the evolution, the leaves wilt and fall. The fall of the leaves as you went along was caused by the dieback of the plant due to the alteration of the libéroligneux vessels which are no longer able to drive the water from the roots to the leaves (Delattre, 1973).

\section{Preparation of inoculum}

Agar fragments of FOV 14 days old were collected and then crushed under sterile conditions in the presence of $5 \mathrm{~mL}$ of sterile distilled water. The maceration was filtered on sterile gauze, which retains the mycelium fragments and allows the spores to pass through. About $1 \mathrm{~mL}$ of this filtrate was deposited by Petri dish containing the PDA medium and incubated for seven days under the same conditions as before. The resulting FOV colonies were then submerged with $5 \mathrm{~mL}$ of sterile distilled water containing a drop of tween 20 . The culture surface was gently scraped with a curved, sterile Pasteur pipette to obtain a spore suspension. This method of obtaining the inoculum allows to avoid possible morphological variations. The concentration of the inoculum was determined using a cell of improperly and then adjusted to $104 / \mathrm{mL}$. 


\section{Inoculation of 14-day-old cotton vivoplants}

The pathogenicity of FOV was demonstrated in the inoculant of 14-day-old cotton and two-to three-leaf stages. Seedlings were obtained by in vivo germination of cotton seeds in pots. On these seedlings, stings were made at the roots using a sterile needle and scarifications using a sterile scalpel blade. Subsequently, inoculum volumes of $50,100,500$, and $1000 \mu \mathrm{L}$ were deposited at the base of each cotton plant to investigate the dose of inoculum capable of causing the disease. The follow-up of the symptoms of the disease caused by FOV was achieved by observation with the naked eye. The experiment was stopped when dead plants were obtained for developing the disease and the mortality rate of the vivoplants was estimated. 10 vivoplants were used for each dose of inoculum and the experiment was repeated three times.

\section{Reisolating the fungus}

To confirm the presence and virulence of the inoculated isolate, the vitroplants used for the pathogenicity test and with symptoms of the disease, including the (uninfected) control, were recovered to perform a reisolation of the pathogen. The reisolation was made from stem fragments because the fusarium wilt caused by FOV is a vascular disease, the presence of the fungus is much more pronounced in the stem (Delattre, 1973). The transplantation of $0.5 \mathrm{~cm}$ stem fragments was made in petri dishes on the $8 \%$ PDA Medium, previously sterilized in autoclave at $120^{\circ} \mathrm{C}$ for $30 \mathrm{~min}$. Petri dishes were then incubated for seven days in a culture room at a temperature of $25^{\circ} \mathrm{C}$ with a $12 \mathrm{~h}$ photoperiod. The fungal cultures obtained are compared to the parent strain.

\section{Characterization and identification of isolated fungal strains}

The different fungal strains obtained after isolation and transplantation were identified after a week of culture on a PDA medium using the Botton et al. (1990).

\section{Action of methyl jasmonate and ethephon on Fusarium oxysporum f. sp. vasinfectum}

The purpose of this test is to evaluate the non-fungal effect of methyl jasmonate and ethephon on the growth of mycelia of Fusarium oxysporum f. sp. vasinfectum (FOV). Agar fragments approximately $0.5 \mathrm{~cm}$ in diameter containing the fungus were transferred to the hood in petri dishes containing the PDA medium to which a volume $\mathrm{V}(0.5 ; 1$ and $2 \mathrm{~mL})$ of methyl jasmonate and ethephon was added. The petri dishes thus sown were incubated for 14 days in a culture room at a temperature of $25^{\circ} \mathrm{C}$ with a $12 \mathrm{~h}$ photoperiod. In the witness, the PDA medium does not contain stimulators. The growth of FOV grown on enriched media in stimulators is compared with that of the control (without stimulators).

\section{Inoculation of cotton plants pretreated in the field}

Inoculation of cotton seedlings in the field was carried out $72 \mathrm{~h}$ after treatment with stimulators. This time corresponding to the best incubation time of the stimulators for the biosynthesis of phenolic compounds. During inoculation, wounds were made at the neck of the seedlings by punctures with a sterile needle and scarifications with a sterile scalpel blade. Second, the 30-day cotton previously treated by stimulators are inoculated with FOV by depositing about $2 \mathrm{ML}$ of spore suspension at the base of each plant [15]. In this experiment, only the dose of inoculum with the best pathogenicity rate in 14-day-old cotton was retained. Five treatment modalities were carried out:

-Plant not treated by SDN and not inoculated with FOV (NTP);

-Plant not treated by the SDN and inoculated with FOV (PNTi);

-Plant treated with methyl jasmonate and inoculated with FOV (PTMi);

-Plant treated with ethephon and inoculated with FOV (PTEi); 
-Plant treated by the association of Methyl jasmonate and Ethephon, then inoculated with FOV (PTEMi).

For each treatment modality, 20 cotton were used. The experiment was repeated three times. The incidence of the disease caused by FOV was evaluated every 10 days up to the 150th day after inoculation.

\section{Evaluation of the effectiveness of the SDN on Fusarium wilt}

Another way to assess the degree of protection of cotton from fusarium wilt was to determine the growth parameters. It is to measure the height and diameter of the stem, to count the healthy leaves (intact), the content of foliar pigments (chlorophylls and carotenoids). This makes it possible to assess the photosynthetic activity and an evaluation of the lignin rate was carried out.

\section{Evaluation of photosynthetic activity}

Evaluation of photosynthetic activity of treated and inoculated cotton leaves at FOV was conducted every 30 days.

\section{Extraction and dosage of leaf pigments}

The extraction and the determination of the leaf pigments were carried out according to the method described by Lichtenthaler (2001). Thus, $200 \mathrm{mg}$ of treated and inoculated leaves were cut into small pieces and placed in test tubes containing $5 \mathrm{~mL}$ of $20 \%$ acetone. It was kept in the dark at $4{ }^{\circ} \mathrm{C}$ for 2 hours. These pieces of leaves were then crushed in acetone in the presence of a pinch of calcium carbonate and Fontainebleau sand. The extraction residue was washed twice with acetone. The ground material was centrifuged at $5.000 \mathrm{rpm}$ for $15 \mathrm{~min}$ at $4{ }^{\circ} \mathrm{C}$. The supernatant obtained constituted the crude extract of chlorophylls. The mass of the crushed leaves and the volume of the crude extract were determined and the absorbance, measured spectrophotometer at 470 $\mathrm{nm}, 647 \mathrm{~nm}$ and $663 \mathrm{~nm}$ against a control sample made with acetone. The chlorophyll contents $\mathrm{a}, \mathrm{b}$ and total ( $\mathrm{Chl} \mathrm{a,} \mathrm{Chl} \mathrm{b} \mathrm{and} \mathrm{Chl}$ t) and carotenoid leaves expressed in $\mu \mathrm{g} / \mathrm{mL}$ was then calculated using the following formulas:

$\mathrm{Chl} \mathrm{a}(\mu \mathrm{g} / \mathrm{mL})=[12,25 \times \mathrm{DO} 663-2,79 \times \mathrm{DO} 647] \times \mathrm{V} / 1000 \mathrm{~m}$

Chl b $(\mu \mathrm{g} / \mathrm{mL})=[21,5 \times \mathrm{DO} 647-5,10 \times \mathrm{DO} 663] \times \mathrm{V} / 1000 \mathrm{~m}$

Chl t $(\mu \mathrm{g} / \mathrm{mL})=[7,15 \times \mathrm{DO} 663+18,71 \times \mathrm{DO} 647] \times \mathrm{V} / 1000 \mathrm{~m}$

$\operatorname{Car}(\mu \mathrm{g} / \mathrm{mL})=[1000 \times \mathrm{DO} 470-1,82 \times \mathrm{chl} \mathrm{a}-85,02 \times \mathrm{chl} b] / 198 \times \mathrm{V} / 1000 \mathrm{~m}$

Where $V$ is the volume of the crude extract $(\mathrm{mL})$ and $\mathrm{m}$ is the mass of the fresh leaves used $(\mathrm{g})$.

\section{Production gain in foliar pigments}

The gain in leaf pigment production (GPF), induced by the application of SDN, was determined relative to the control. It was expressed as a percentage and calculated according to the formula:

GPF $(\%)=[(P$ test $-\mathrm{P}$ control $) / P$ control $] \times 100$

Where $\mathrm{P}$ is the content of leaf peppers (chlorophylls $\mathrm{a}, \mathrm{b}$, total and carotenoids).

\section{Evaluation of lignin content in treated and inoculated leaves}

For this study, the effect of SDN on the lignification of cotton plants was evaluated in roots, stems and leaves. These samples were harvested 90 days after inoculation with the pathogen, when the first symptoms of FOV started to appear on untreated and inoculated cotton plants (PTNI). 


\section{Grinding of cotton samples}

The harvested cotton samples were freeze-dried. Then, $10 \mathrm{~g}$ of each sample was weighed and ground in a mortar to obtain powder samples on which lignin extraction and assaying was performed (Figure 1).
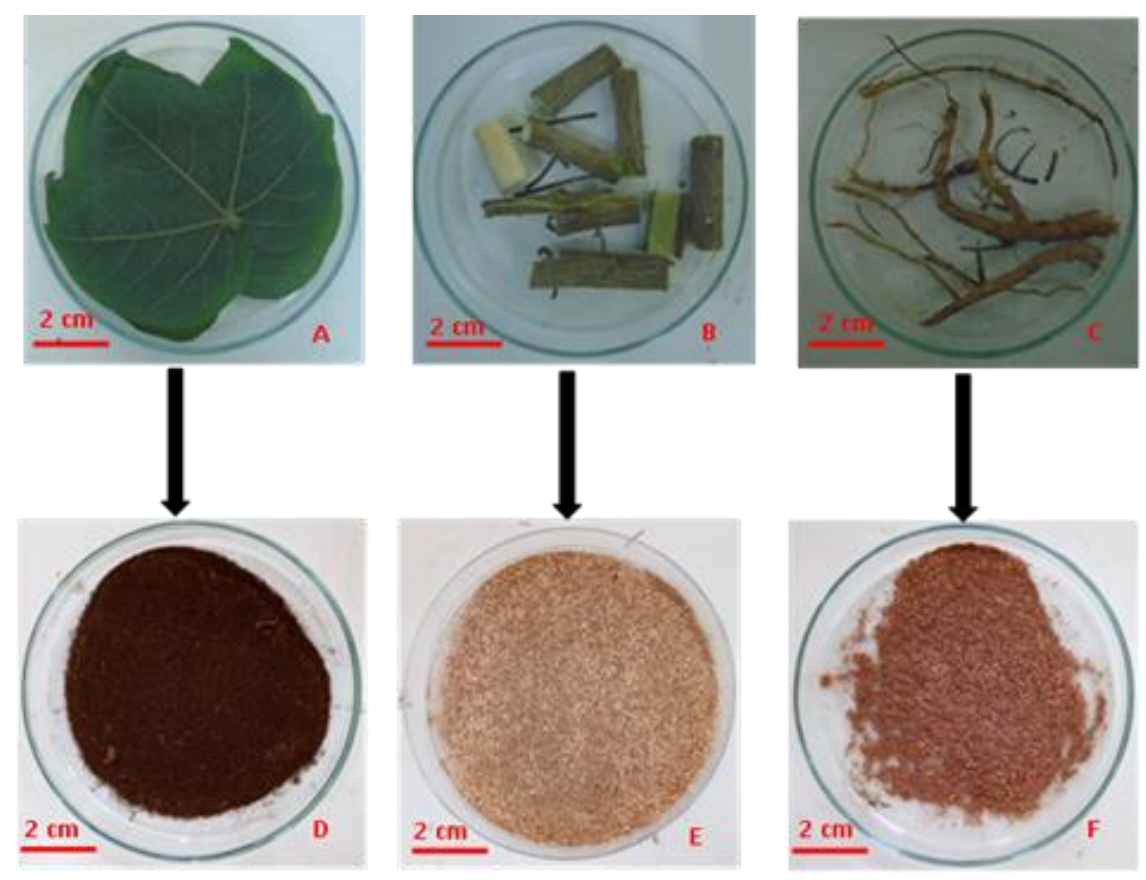

Figure 1. Cotton Explants Treated with Natural Defense Stimulators $(A, B$ and $C)$ and inoculated with FOV and their respective homogenates $(D, E$ and $F)$

FOV: Fusarium oxysporium f.sp. vasinfectum; SDN: natural defense stimulators; A: cotton leaves; B: Cotton stems; C: cotton roots; D: cotton leaf powder; E: cotton stalk powder; F: cotton root powder

\section{Extraction and dosage of lignins}

The extraction and the determination of the lignins were carried out according to the method of Ellis (1946). The extraction of lignins took place in four essential stages.

First step: $0.9 \mathrm{~g}$ of powder from each sample were weighed and put into cotton fabrics and tied with a thread. These wood powder samples successively underwent two hot extractions with $96 \%$ ethanol and with water. The organic solvent was used to remove single phenolic acids and polyphenols while the aqueous solvent allowed the removal of water-soluble compounds such as proteins and tannins. This analytical step was aimed at extracting the soluble compounds present in the cottonwood powder which would subsequently interfere with the lignins during their dosages. The samples were then dried in an oven for 18 hours at $105^{\circ} \mathrm{C}$.

Second step: After cooling, the dry powder samples were each poured into a two-liter Erlenmeyer flask containing one liter of $96 \%$ ethanol. The Erlenmeyer flask is placed on a heated magnetic stirrer. When the ethanol began to boil, the mixture was stirred for $30 \mathrm{~min}$ using a magnetic stirrer to remove the maximum of phenolic compounds. Then the ethanol was emptied and replaced with one liter of water; which allowed the extraction of more polar compounds. This step was repeated successively twice with ethanol and once with water.

Third step: the samples were then recovered and put in an oven for drying for $18 \mathrm{~h}$ at $105^{\circ} \mathrm{C}$; then cooled. The powders of samples thus dried were used for the determination of the lignins. 
Fourth step: this step allowed to degrade the cellulose still contained in the samples. Thus, $0.2 \mathrm{~g}$ of powder of each sample was weighed (mass of the test portion). Each sample was placed in a crucible ( $250 \mathrm{~mL}$ glass bottle) previously put in the oven and weighed after cooling (anhydrous mass crucible). Then $5 \mathrm{~mL}$ of $72 \%$ sulfuric acid was added to each crucible. Then, they were placed on a magnetic stirrer for stirring at room temperature for two hours. After this etching time, $115 \mathrm{~mL}$ of distilled water was added to each crucible to effect hydrolysis with $3 \%$ sulfuric acid. The crucibles were then autoclaved at $120^{\circ} \mathrm{C}$ for one hour; which made it possible to burst the maximum number of cells that were not in the previous step, in order to let out all the lignins of the cells. For the determination of the lignins, the contents of each crucible were filtered and the pellet was washed several times with distilled water in order to remove the cellulose which would still be retained in the wood fibers. After washing, the pellet was dried in an oven at $105^{\circ} \mathrm{C}$ for $18 \mathrm{~h}$, then returned to the crucibles and weighed (mass crucible with residue). The lignin content was expressed as a percentage and calculated according to the formula:

Lignin content $(\%)=\frac{\text { Mass of residue }}{\text { Mass of the test sample }}$

Where, Residue mass $=$ Crucible mass with residue - Anhydrous crucible mass

\section{Statistical analysis}

Statistical analysis were performed using the STATISTICA 7.1 software. An analysis of variance (ANOVA) was performed on all applied treatments. When this analysis shows a difference between the means, the NewmanKeuls test is performed in order to determine the significant differences between treatments at the $5 \%$ threshold. For percent values, the Kruskal-Wallis test was used to determine significant differences $(P<0.05)$ between treatments.

\section{Results}

\section{Characterization of the purified isolate}

After purification of the isolate by monospore culture, only one morphological group was observed among the offspring. The aerial mycelium had a whitish downy appearance with a purplish, sparse, and sparse background. Microscopic observation revealed the presence of a compartmentalized thallus with short microphialids on which many microconidia are found as well as macroconidia and chlamydospores (Figure 2). These characteristics indicate the presence of Fusarium oxysporum.
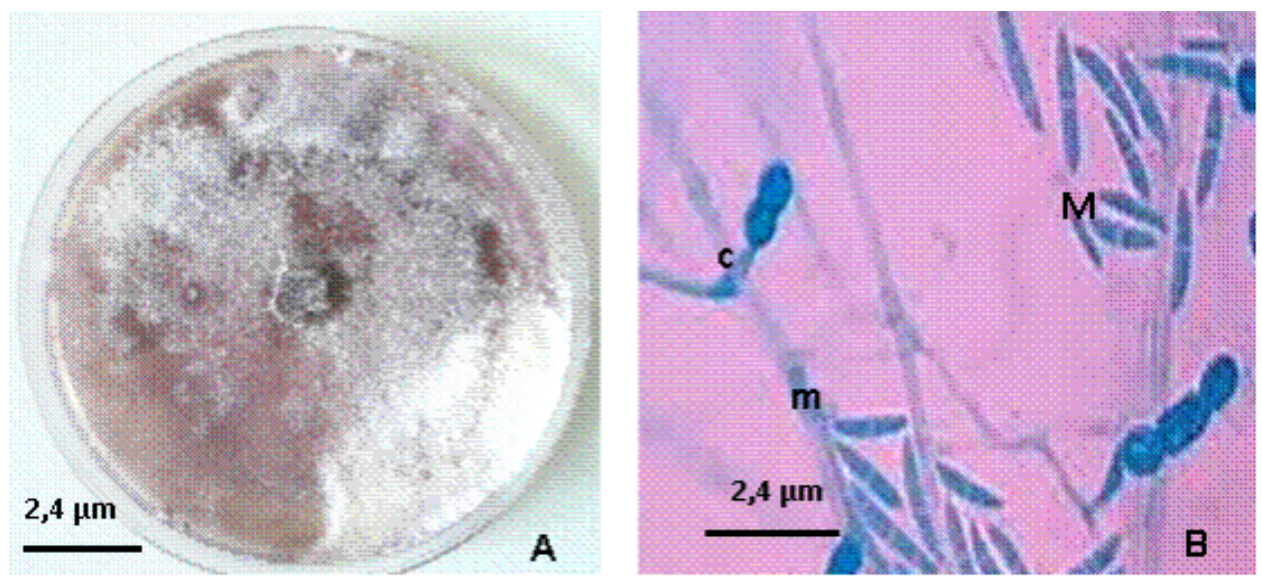

Figure 2. Morphological description of a virulent FOV strain 
A: macroscopic appearance; B: microscopic appearance; c: chlamydospore; m: microconidia; M: macroconidia; FOV: Fusarium oxysporum f. sp. vasinfectum

\section{Pathogenicity of FOV}

The pathogenicity test for FOV, the causal agent of Fusarium wilt, was carried out on 14-day-old vivoplants. The results obtained are shown in Table I. All the amounts of inoculum used (50;100; 500 and $1.000 \mu \mathrm{L}$ ) induced wilting of the leaves and stems after seven days. However, the aggressiveness of FOV or the severity of the disease varied with the dose of inoculum. In fact, although the cotton plants inoculated with $50 \mu \mathrm{L}$ of spore suspension showed symptoms of wilting, they remained alive. On the other hand, cottonwood inoculated with 100; 500 and $1.000 \mu \mathrm{L}$ of inoculum had wilted and necrotic leaves and stems. However, the 500 and $1.000 \mu \mathrm{L}$ doses of FOV inoculum were more pathogenic, with symptoms occurring 21 days after inoculation resulting in the death of almost all the seedlings $(97.84 \%$ mortality by $500 \mu \mathrm{L}$ and $100 \%$ mortality per $1.000 \mu \mathrm{L})$. The seedlings inoculated with $100 \mu \mathrm{L}$ of inoculum developed less severe symptoms with $10.47 \%$ mortality rate. On the control seedlings, there was no manifestation of symptoms of the disease (Figure 3 ).

Table 1. Pathogenicity Testing of FOV inoculum

\begin{tabular}{cccccc}
\hline $\begin{array}{c}\text { Volume of } \\
\text { inoculum } \\
(\mu \mathrm{L})\end{array}$ & $\begin{array}{c}\text { Leaf } \\
\text { yellowing }\end{array}$ & Leaf wilt & $\begin{array}{c}\text { Withering from } \\
\text { the stem }\end{array}$ & $\begin{array}{c}\text { Rate of } \\
\text { mortality } \\
(\%)\end{array}$ & Profile \\
\hline 0 & - & - & - & 0 & $\begin{array}{c}\text { non } \\
\text { pathogenic }\end{array}$ \\
50 & - & - & - & 0 & $\begin{array}{c}\text { non } \\
\text { pathogenic }\end{array}$ \\
100 & +++ & +++ & + & 10.47 & pathogenic \\
500 & +++++ & +++++ & ++++ & 97.84 & pathogenic \\
1.000 & +++++ & +++++ & ++++ & 100 & pathogenic \\
\hline
\end{tabular}

FOV: Fusarium oxysporum f. sp. vasinfectum; (-): absence; (+): presence 



Figure 3. Manifestation of the external symptoms of Fusarium wilt on cotton plants inoculated with different doses of FOV inoculum

FOV: Fusarium oxysporum f.sp. vasinfectum; A: witness; B: $50 \mu \mathrm{L}$ of FOV inoculum after 21 days of incubation; C: $100 \mu \mathrm{L}$ of FOV inoculum after 21 days of incubation; D: $500 \mu \mathrm{L}$ of FOV inoculum after 21 days of incubation; $\mathrm{E}$ : $1,000 \mu \mathrm{L}$ of FOV inoculum after 21 days of incubation

Reisolation of the fungus was performed with inoculated cotton seedling fragments and uninoculated vivoplant stem fragments (control). After seven days of incubation, the inoculated stem fragments developed fungal mycelia on the PDA medium (Figure 4) contrary to the control.

The mushroom colonies showed a whitish downy appearance with a purplish, sparse, and sparse background. Microscopic observation showed numerous ovoid and group macroconidia and more or less curved fusoid microconidia. These morphological characteristics of the reisolated fungus strain showed no variation compared to those of the parent culture (purified isolate). After characterization, the key of Botton et al. (1990) identified isolated fungal strains as Fusarium oxysporum f. sp. In addition, the isolate (1000 $\mu \mathrm{L}$ of inoculum) that was able to cause $100 \%$ mortality in all inoculated cotton seedlings confirmed the special form "vasinfectum" of our species Fusarium oxysporum.

\section{Effect of methyl jasmonate and ethephon on Fusarium oxysporum f. sp.vasinfectum}

Methyl jasmonate and ethephon were added to the culture medium of Fusarium oxysporum f. sp. vasinfectum (FOV) to see their effect on the growth of FOV mycelium. The results showed that the stimulators do not have a negative effect on the growth of the FOV mycelium. Whatever stimulator is used, mycelium growth occurs. Compared to the control, growth of the mycelium was better in the presence of the stimulators. Thus, the evolution front is $1.7 \mathrm{~cm}$ in Petri dishes containing ethephon; $1.8 \mathrm{~cm}$ in petri dishes containing methyl jasmonate and $1.9 \mathrm{~cm}$ in those combining the two stimulators against $1.6 \mathrm{~cm}$ in the control. On the other hand, aerial mycelium having a whitish downy appearance with a purplish, shallow, sparse bottom is observed in all petri dishes (Figure 5). In addition, microscopic observation showed the presence of a compartmentalized thallus with short microphialids on which many microconidia are found as well as macroconidia and chlamydospores (Figure 
6). These characteristics clearly indicate according to the key of Botton et al. (1990) that the fungus grown on PDA medium containing SDN is indeed FOV.
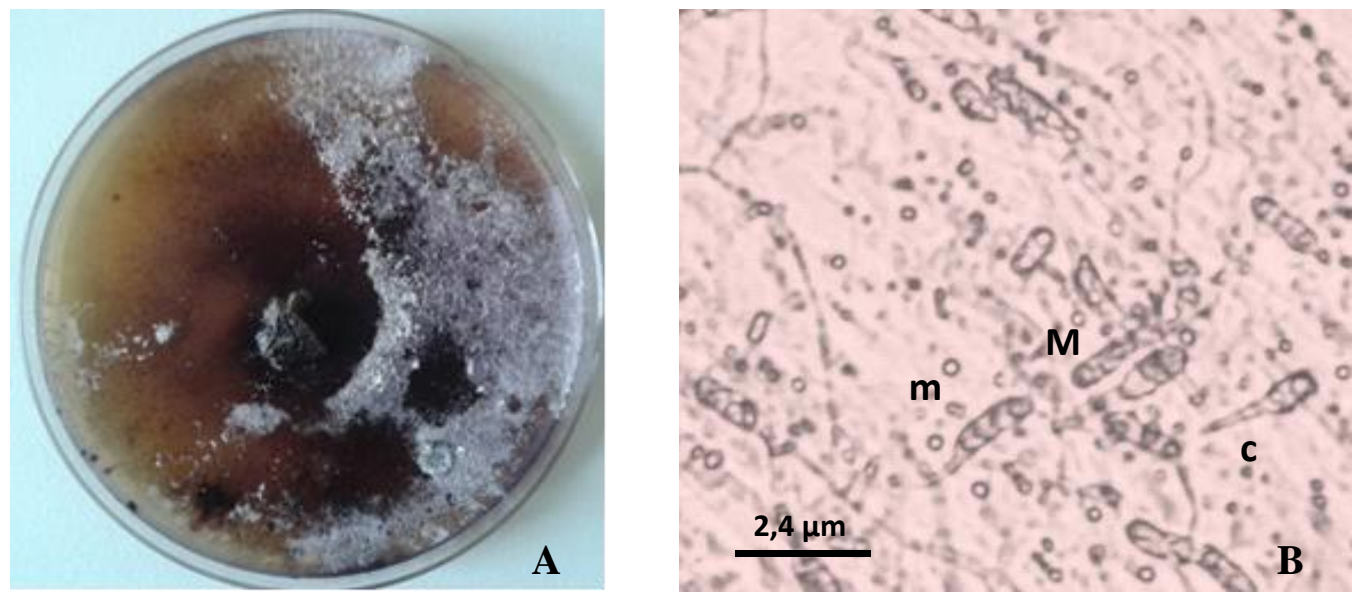

Figure 4. Macroscopic and microscopic appearance of the virulent FOV strain extracted from cotton buds inoculated with $1.000 \mu \mathrm{L}$ of inoculum

FOV: Fusarium oxysporum f. sp. vasinfectum; A: macroscopic appearance; B: microscopic appearance; C: chlamydospore; m: microconidia; M: macroconidia
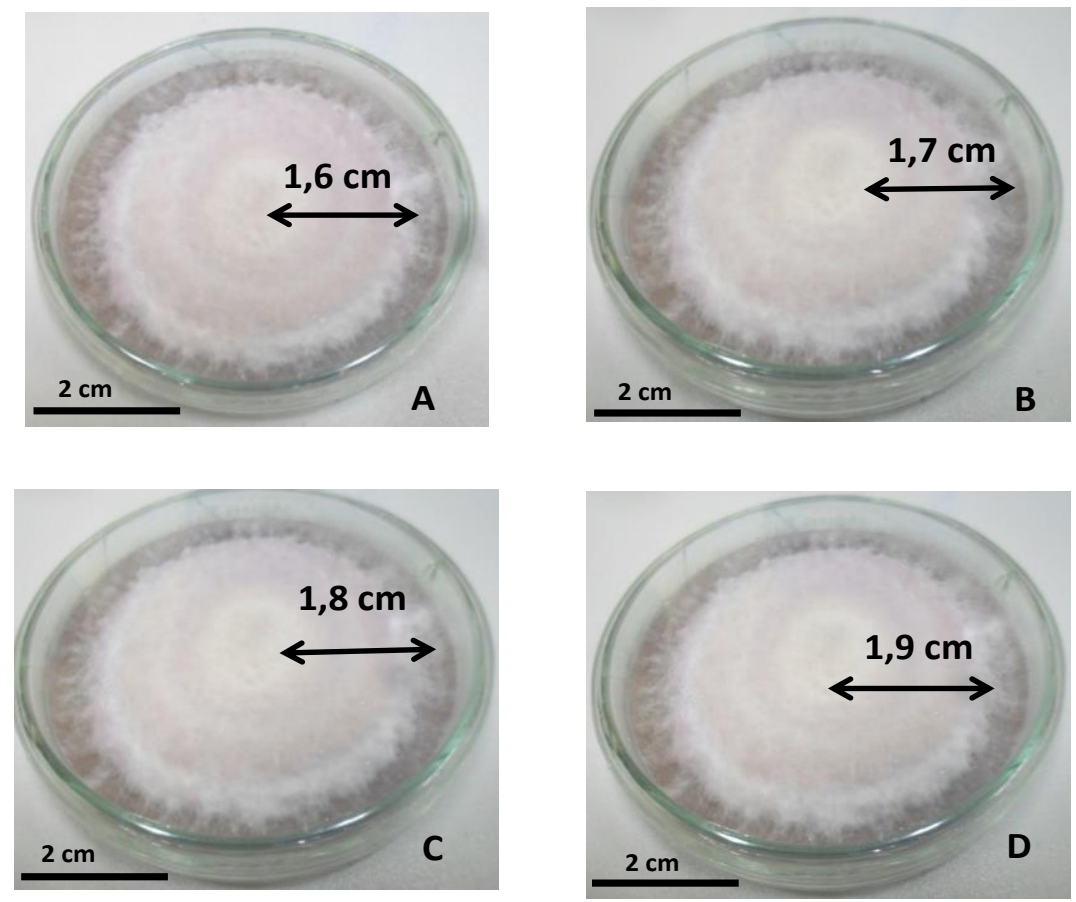

Figure 5. Macroscopic appearance of FOV strain grown on PDA medium containing stimulators

MeJA: methyl jasmonate; FOV: Fusarium oxysporum f. sp. vasinfectum; PDA, potato dextrose agar; A: containing medium containing no stimulators (control); B: medium containing ethephon; C: medium containing MeJA; D: medium containing the association of MeJA and ethephon; : forehead of evolution of the mycelium

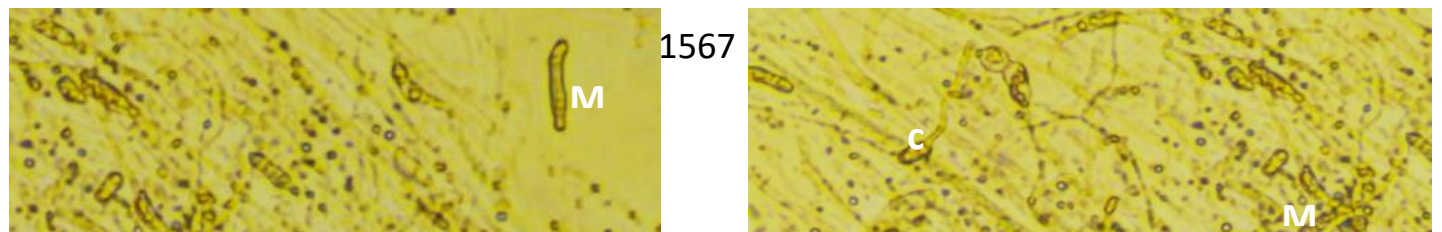


Figure 6. Microscopic appearance of the strain of FOV grown on PDA medium

FOV: Fusarium oxysporum f. sp. vasinfectum; PDA: potato dextrose agar; A: PDA medium containing no stimulator (control); B: PDA medium containing the stimulator; $\mathrm{m}$ : microconidia; M: macroconidia; $\mathrm{c}$ : chlamydospore.

\section{Evaluation of physiological status of treated and inoculated cotton plants}

The degree of protection of the cotton plant against FOV or the physiological state of the treated plants was evaluated by determining the leaf pigment content.

\section{Chlorophyll Pigments and Carotenoids}

The evaluation of the physiological state of the cotton plants was carried out by determining the content of chlorophyll $a, b$, total and carotenoids in the leaves. The effect of exogenous stimulator application on total chlorophyll $\mathrm{a}$, b and carotenoid content in FOV-inoculated cotton leaves is shown in Tables II. The results showed that at D0, total chlorophyll content is almost identical for all treatments, as well as for control cotton. From J30 to J60, total chlorophyll content decreased for all treatments and for PNTi. This decrease is more pronounced in the $\mathrm{J} 90$ for all treatments and PNTi, while for PNT, it remains almost invariable. From J120 to J150, total chlorophyll content increases for all treatments. This content is higher in PTEMi $(479.07 \mu \mathrm{g} / \mathrm{mL}$, a gain of 96.52 \%). In the PTMi, the content is $396.23 \mu \mathrm{g} / \mathrm{mL}$, a gain of $65.52 \%$, while in the PTEi this content is $325.22 \mu \mathrm{g} / \mathrm{mL}$ for a gain of $33.74 \%$. On the other hand, for PTNi, the drop in content that began on day 30 continues and increases more to become zero in J150. In PNT, the content remains almost identical to that of J0 $(244.07 \mu \mathrm{g} / \mathrm{mL})$.

Concerning the variation of the content of chlorophylls (a) and of chlorophylls (b), the contents are almost identical at the level of the treatments as well as, in the control plants at day 0 . However, the content of chlorophylls (a) is higher than that of chlorophyll (b). From J30 to J60, the chlorophyll content (a) decreases for all treatments and in PNTi, while the chlorophyll content (b) increases. In PNT, they remain almost identical to those of J0. This drop in chlorophyll content (a) is more pronounced in J90. From J120 to J150, chlorophyll (a) and chlorophyll (b) levels increase for all treatments. Thus, in J150 in PTEMi, the chlorophyll content (a) is 300.04 $\mu \mathrm{g} / \mathrm{mL}$ against $162.03 \mu \mathrm{g} / \mathrm{mL}$ for chlorophyll (b), in PTMi, the chlorophyll a content is $246.19 \mu \mathrm{g} / \mathrm{mL}$ compared with $150.04 \mu \mathrm{g} / \mathrm{mL}$ for chlorophyll (b), while for chlorophylls the chlorophyll content is $197.10 \mu \mathrm{g} / \mathrm{g}$

MF versus $128.12 \mu \mathrm{g} / \mathrm{mL}$ for chlorophylls (b). On the other hand, in PNTi, the chlorophyll (a) and chlorophyll (b) contents become nil. However, in PNT, these levels remained almost identical.

The variation of the carotenoid content in the cotton leaves is similar to that of the chlorophyllian pigments Thus, from day 0 to $\mathrm{J} 150$, in the PTEMi, the carotenoid content is passed from 27.09 to $128.50 \mu \mathrm{g} / \mathrm{mL}$, a gain of $374.34 \%$, followed respectively by PTMi (from 26.73 to $119.16 \mu \mathrm{g} / \mathrm{mL}$, a gain of $345.79 \%$ ) and PTEi (from 28.04 
to $91.80 \mu \mathrm{g} / \mathrm{mL}$, a gain of $227.38 \%$ ). In PNT, the carotenoid content increased from 27.07 to $71.10 \mu \mathrm{g} / \mathrm{mL}$, a gain of $162.65 \%$, while in PNTi the carotenoid content decreased from 28.53 to $0 \mu \mathrm{g} / \mathrm{mL}$, a loss of $100 \%$.

Table 2. Effect of stimulators on variation of leaf pigment content in cotton leaves inoculated with FOV from D0 to $\mathrm{D} 150$ 


\begin{tabular}{|c|c|c|c|c|c|c|}
\hline \multirow{3}{*}{$\begin{array}{c}\mathrm{TI} \\
\text { (hour) }\end{array}$} & \multirow{3}{*}{$\begin{array}{l}\text { Nature of } \\
\text { pigment }\end{array}$} & \multicolumn{5}{|c|}{ Leaf pigment content $(\mu \mathrm{g} / \mathrm{mL})$} \\
\hline & & \multicolumn{5}{|c|}{ Treatement } \\
\hline & & PNTi & PNT & PTEi & PTMi & PTEMi \\
\hline \multirow{4}{*}{0} & Chla & $123,25 \pm 0,24 a$ & $123,05 \pm 2,11 a$ & $125,10 \pm 2,03 a$ & $121,29 \pm 2,21 a$ & $124,50 \pm 1,16 a$ \\
\hline & Chlb & $87,30 \pm 1,09 a$ & $89,02 \pm 0,21 a$ & $91,06 \pm 1,17 a$ & $88,48 \pm 1,07 a$ & $87,37 \pm 2,02 a$ \\
\hline & Chlt & $242,55 \pm 1,52 a$ & $243,07 \pm 0,93 a$ & $243,16 \pm 1,55 a$ & $243,77 \pm 2,11 a$ & $241,87 \pm 1,40 a$ \\
\hline & Car & $28,53 \pm 2,71 a$ & $27,07 \pm 0,93 a$ & $28,04 \pm 1,22 a$ & $26,73 \pm 1,05 a$ & $27,09 \pm 2,40 a$ \\
\hline \multirow{4}{*}{30} & Chla & $122,47 \pm 1,09 \mathrm{e}$ & $140,58 \pm 1,09 d$ & $150,78 \pm 1,09 c$ & $166,47 \pm 1,09 b$ & $188,58 \pm 1,09 a$ \\
\hline & Chlb & $115,53 \pm 1,09 c$ & $104,49 \pm 1,09 b$ & $132,27 \pm 1,09 a$ & $125,64 \pm 1,09 a$ & $113,44 \pm 1,09 b$ \\
\hline & Chlt & $239,17 \pm 0,84 d$ & $245,07 \pm 0,88 c$ & $283,05 \pm 1,02 b$ & $292,11 \pm 0,65 a$ & $300,02 \pm 1,37 a$ \\
\hline & Car & $24,21 \pm 2,35 c$ & $25,24 \pm 0,27 c$ & $40,26 \pm 2,02 b$ & $50,22 \pm 0,13 a$ & $57,11 \pm 1,31 a$ \\
\hline \multirow{4}{*}{60} & Chla & $111,42 \pm 1,09 d$ & $136,56 \pm 1,09 b$ & $145,48 \pm 1,09 b$ & $148,48 \pm 1,09 b$ & $174,56 \pm 1,09 a$ \\
\hline & Chlb & $103,81 \pm 1,09 c$ & $103,51 \pm 1,09 c$ & $111,88 \pm 1,09 b$ & $129,55 \pm 1,09 a$ & $113,57 \pm 1,09 b$ \\
\hline & Chlt & $215,23 \pm 0,71 f$ & $240,07 \pm 0,21 d$ & $257,36 \pm 1,31 \mathrm{c}$ & $278,03 \pm 1,22 b$ & $288,13 \pm 2,21 a$ \\
\hline & Car & $20,08 \pm 2,22 c$ & $26,12 \pm 1,15 c$ & $36,32 \pm 1,16 c$ & $48,16 \pm 2,41 a$ & $51,35 \pm 2,36 a$ \\
\hline \multirow{4}{*}{90} & Chla & $65,02 \pm 1,11 c$ & $136,03 \pm 1,16 c$ & $70,28 \pm 0,29 b$ & $74,54 \pm 1,22 b$ & $86,48 \pm 0,15 a$ \\
\hline & Chlb & $69,05 \pm 0,02 c$ & $104,04 \pm 2,55 b$ & $126,20 \pm 1,37 a$ & $120,40 \pm 0,11 a$ & $121,20 \pm 1,31 a$ \\
\hline & Chlt & $134,07 \pm 1,03 d$ & $245,07 \pm 0,01 \mathrm{lc}$ & $198,48 \pm 1,13 b$ & $231,94 \pm 0,33 a$ & $235,68 \pm 0,34 a$ \\
\hline & Car & $20,08 \pm 2,22 c$ & $26,12 \pm 1,15 c$ & $36,32 \pm 1,16 b$ & $48,16 \pm 2,41 a$ & $51,35 \pm 2,36 a$ \\
\hline \multirow{6}{*}{120} & Chla & $45,48 \pm 1,09 f$ & $135,48 \pm 1,09 d$ & $186,25 \pm 1,09 c$ & $232,48 \pm 1,09 b$ & $255,48 \pm 1,09 a$ \\
\hline & Chlb & $36,59 \pm 1,09 f$ & $103,66 \pm 1,09 c$ & $114,07 \pm 1,09 b$ & $146,1 \pm 1,09 b$ & $203,09 \pm 1,09 a$ \\
\hline & Chlt & $82,07 \pm 1,33 f$ & $255,14 \pm 2,66 d$ & $300,32 \pm 0,22 c$ & $378,58 \pm 2,16 b$ & $458,57 \pm 1,72 a$ \\
\hline & Car & $14,11 \pm 2,08 \mathrm{~g}$ & $25,17 \pm 1,21 d$ & $49,78 \pm 1,17 b$ & $57,36 \pm 1,23 b$ & $74,30 \pm 0,22 a$ \\
\hline & Chla & - & $124,05 \pm 1,13 e$ & $197,10 \pm 1,23 c$ & $246,19 \pm 0,28 b$ & $300,04 \pm 0,93 a$ \\
\hline & Chlb & - & $110,02 \pm 0,56 \mathrm{e}$ & $128,12 \pm 0,09 c$ & $150,04 \pm 0,19 b$ & $162,03 \pm 0,49 a$ \\
\hline
\end{tabular}




\begin{tabular}{lllllll}
\hline 150 & Chlt & - & $250,07 \pm 2,40 \mathrm{~d}$ & $325,22 \pm 1,07 \mathrm{c}$ & $396,23 \pm 1,47 \mathrm{~b}$ & $479,07 \pm 2,42 \mathrm{a}$ \\
& Car & - & $71,10 \pm 1,24 \mathrm{~d}$ & $91,80 \pm 1,24 \mathrm{c}$ & $119,16 \pm 1,04 \mathrm{~b}$ & $128,50 \pm 2,12 \mathrm{a}$ \\
& & & & & \\
\hline
\end{tabular}

FOV: Fusarium oxysporum f. sp. vasinfectum; TI: incubation time; PNT: untreated and uninoculated plant; PNTi: untreated and inoculated plant; PTEi: plant treated with ethephon and inoculated; PTMi: plant treated with MeJA and inoculated; PTEMi: plant treated by the association of MeJA and ethephon; $\pm \mathrm{S}$ : standard error; on the same line, the values followed by the same letter are not significantly different (Newman-Keuls test at 5\%); the values represent the average of three repetitions.

\section{Effect of natural defense stimulators on the variation of lignin}

Figure 28 shows the influence of exogenous application of SDN on the evolution of lignin levels in cotton roots, stems and leaves after 150 days of FOV inoculation. Thus, the lignin content increased in the roots of treated cotton plants compared to controls. Cotton trees treated with the combination of methyl jasmonate and ethephon, then inoculated (PTEMi) had the highest lignin level $(76.87 \%)$, followed by cotton plants treated with methyl jasmonate and inoculated (PTMi) with a rate of $64.23 \%$, while those treated with ethephon and inoculated (PTEi) had a rate of $56.47 \%$. As for controls, lignin levels remained statistically identical $(14.56 \%$ for PNTi and $15.66 \%$ for PNT).

In the stems, the results also showed an increase in the lignin content in treated cotton compared with controls. This evolution of the lignin level in the stems is similar to that obtained in the roots. Thus, PTEMi had the highest lignin level (41.87 \%), followed by PTMi with a rate of $38.23 \%$, while PTEi had a rate of $34.48 \%$. As for the PNTi and PNT, the rates remained statistically identical (4.06 \% for PNTi and $5.62 \%$ for PNT).

The report is the same at the leaf level. The controls had the lowest levels (1.78 \% for PNTi and $2.52 \%$ for PNT), while in treated and inoculated plants, an increase was observed. Thus, PTEMi had the highest lignin level (18.26 \%), followed by PMTi (12.08 \%) and PTEi (9.17\%).

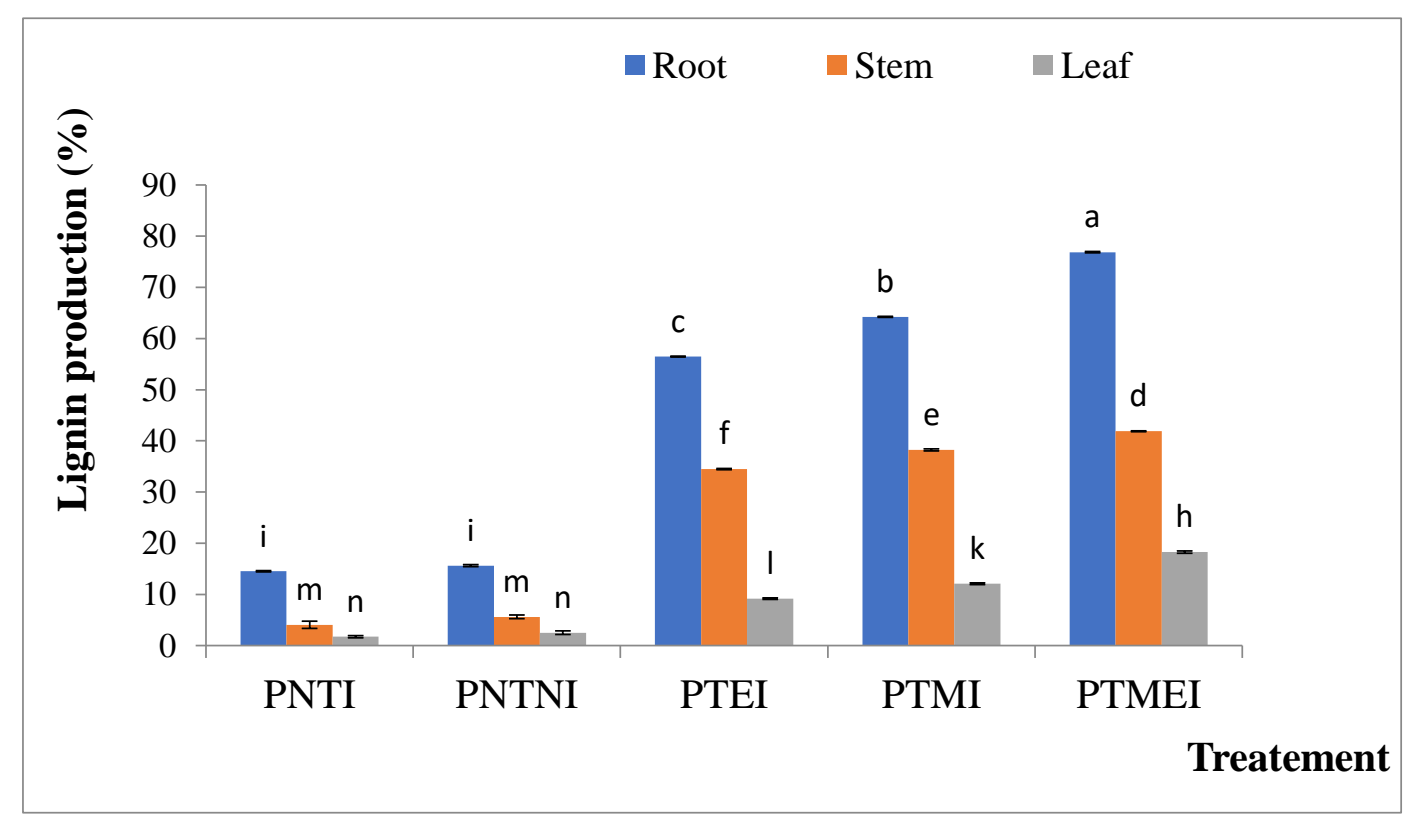

Figure 7. Evolution of lignin content in cotton explants treated with stimulators and inoculated with FOV 
MeJA: methyl jasmonate; FOV: Fusarium oxysporum f. sp. vasinfectum; PNT: untreated and uninoculated plant; PNTi: untreated and inoculated plant; PTMi: plant treated with MeJA and inoculated; PTEi: plant treated with ethephon and inoculated; PTEMi: plant treated by the association of MeJA and ethephon then inoculated. The experiment was repeated three times. Values followed by the same letter are not significantly different $(5 \%$ Kruskal Wallis test).

\section{Discussion}

The whitish, feather-white, shallow, low-density appearance of the mycelium obtained after purification of the fungal isolate, as well as the presence of microconidia, macroconidia and chlamydospores, led to the conclusion that this is Fusarium oxysporum type (Bacchetta et al., 1995, Henni et al., 1998). Inoculation of two-week-old young cotton farmers, followed by almost total mortality, confirmed its virulence. This fact proves the special form "vasinfectum" of our mushroom, responsible for Fusarium wilt in cotton.

Analysis of inoculum concentration variation $(50 ; 100 ; 500$ and $1000 \mu \mathrm{L}$ ) showed that doses between 500 and $1.000 \mu \mathrm{L}$ were more pathogenic. The dose of $100 \mu \mathrm{L}$ of inoculum that allowed $10.47 \%$ mortality rate was described as non-pathogenic, because according to Djerbi (1990), the pathogenicity test of a fungal isolate is valid when the final mortality of plants exceeds $20 \%$.

The treatment of cotton by the SDN has shown a positive influence on the protection against fusariosis caused by FOV. Indeed, the treatment associating MeJA and ethephon allowed a better protection against FOV compared to MeJA or ethephon applied alone. The symptoms of Fusarium wilt caused by the inoculation of FOV in treated cotton plants decreased, disappearing completely on the 150th day. These results seem to show a reversible effect of the symptoms of fusariosis under the action of different SDN. The treated cotton plants therefore behaved like PNTs and better in the PTEMi. The combination of methyl jasmonate and ethephon seems to provide a complementary effect by increasing the efficiency of MeJA or ethephon applied alone. This association would have allowed the establishment of natural defenses by inducing a gain of resistance against FOV. Such results have been reported by Konan et al (2014) in greenhouse cotton growers. Indeed, these authors showed the synergistic effect between MeJA and ethephon in phytoprotection against FOV. As for the PNTi, 100 $\%$ mortality was recorded, thus showing the low level of compounds for the defense of the plant.

In addition, the analysis of leaf pigment levels in treated and inoculated cotton leaves confirms this. Chlorophylls, which are the pigments responsible for the green color of the leaves, represent the "blood of plants" because their molecular structure is close to that of hemoglobin, one of the main constituents of human blood (Stassiaux, 2010). Chlorophylls give plants the power of photosynthesis, that is, the biosynthesis of carbohydrates from the light energy captured by chlorophylls. Thus, under the action of FOV, total chlorophyll content fell in PTNi to cancel at J150. On the other hand, under the action of SDN, the total chlorophyll content has increased steadily showing a positive effect on the biosynthesis of chlorophylls. The total chlorophyll content of the PTEMi was the highest compared to the other treatments and even higher than that of the PTN. This shows a beneficial effect of treatment associating MeJA and ethephon on the biosynthesis of chlorophylls. In addition, the work of Couderchet et al. (2003) showed a strong link between PR proteins, induced phytoalexins and protoporphyrogen oxidase, an enzyme involved in chlorophyll synthesis. However, the combination of MeJA and ethephon stimulates the production of phytoalexins more than that of MeJA or ethephon taken separately. This could explain the significant increase in total chlorophyll content seen in PTEMi compared with other treatments. In addition, the significant decrease in total chlorophyll content in PTNi that vanishes at J150 revealed the influence of FOV on chlorophyll degradation. Indeed, the plant needs sugars to ensure its growth, its development and the establishment of defense mechanisms. The sugars are synthesized in leaves and then transported via the stem to the organs wells of the plant (roots, flowers, leaves). For its part, the heterotrophic fungus for carbon will draw sugars from the tissues it infects. It thus establishes a competition for the carbon resources. The pathogen can then represent a new well that will divert to its profit assimilas flows within the plant. In this competition between the plant and the mushroom, the mobilization of sugars is a major issue for both opponents, cotton trying to defend itself and the fungus to develop (Afoufa-Bastien et al., 2010; Konan, 2014). 
The application of SDN also resulted in an increase in chlorophyll content (a) and a decrease in chlorophyll content (b). Indeed, under the action of SDN, there would have been a bioconversion of chlorophyll (b) to chlorophyll (a), thus increasing the content of chlorophyll a and therefore a good photosynthetic activity (Folly, 2000, Djapic, 2012). As for carotenoid levels, they increase slightly, similarly to those of chlorophyll content b. These results show that the exogenous application of SDN has a beneficial effect on the synthesis of chlorophyll (a). Indeed, chlorophyll (a) is the main pigment, that is to say the most active during photosynthesis because it allows the conversion of light energy into chemical energy in the form of ATP while other pigments (Chlorophyll (b) and carotenoids) that transmit energy to it by resonance are called accessory pigments (Olson, 2006, Raven et al., 2007, N'cho et al., 2018).

,The evaluation of the effect of the SDNs on the reinforcement of the cotton cell walls of FOV-inoculated cotton plants through the quantification of lignins in the roots, stems and leaves, showed an increase of their level in the treated and inoculated plants compared to the witnesses. Indeed, lignins are essential constituents of any wood because they are at the base of the rigid and durable nature of a tree by being deposited in the secondary wall of certain plant cells. Thus, a high lignin level would reduce the chances of a pathogen entering a plant (Maladier, 2014). The results showed significant levels of lignin in the roots, followed by stems and then leaves. Indeed, FOV is a soil fungus, which under favorable conditions invades the roots following the penetration of the epidermis; this promotes the development of disease symptoms in the plant (Bacchetta et al., 1995). The roots are therefore the first organs to be in contact with FOV. Thus, a high level of lignin in it will therefore ensure the strengthening of the cell walls and prevent the penetration of the fungus into the plant. The roots serve as a sort of "shield" to the whole plant. In addition, lignin levels are the same in roots stems and leaves in PTNi and PTN. This shows that the presence of the fungus in the plant does not influence lignin production and metabolism. Therefore, the increase in the level of lignins in the plant would be exclusively due to the exogenous application of SDN on the cotton leaves.

\section{Conclusion}

MeJA and ethephon have shown their ability to induce better resistance of the cotton plant to Fusarium oxysporum f. sp. vasinfectum through the increase in photosynthetic activity and the strengthening of the constitutive defense of the plant by an increase in the lignin content. This protection is more effective after a treatment combining the two molecules.

\section{References}

1. Afoufa-Bastien D., Medici A., Jeauffre J., Coutos-Thevenot P., Lemoine R., Atanassova R., Laloi M. (2010). The Vitis vinifera sugar transporter gene family: phylogenetic overview and macroarray expression profiling. BMC Plant Biology 10: 245-267.

2. Amari L.D.G.E., Chérif M., Kouakou TH., Camara B., Koné D. (2014). Salicylic acid and acibenzolar-s-methyl induced resistance against toxic effect of juglone, a toxin of Mycosphaerella fijiensis causal agent of banana black leaf streak disease. Journal of Advanced in Agriculture 3: 204 - 217.

3. Amari L.D.G.E. (2012). Stratégies d'évaluation et de gestion par stimulation des défenses naturelles des bananiers à l'infection de la maladie des raies noires causée par Mycosphaerella fijiensis Morelet (Mycosphaerellaceae) en Côte d'Ivoire. Thèse de I'Université Félix Houphouët-Boigny, Abidjan, Côte d'Ivoire. pp. 237.

4. Bacchetta G., Belletti P., Brullo S., Cagelli L., Carasso V., Casas J.L., Cervelli C., Escrib Beckman CH., Roberts EM. (1995). On the nature genetic basis for resistance tolerance of fungal wilt diseases. Advances in Botanical Research 21: 35-77.

5. Bouhot D., Rouxel F. (1970). Deux techniques de determination du pouvoir pathogene des Fusarium oxysporum. Annales phytopathologiques 2: 251-254. 
6. Botton B., Breton A., Fevre M., Gauthier S., Guy P.H., Larpent J.P., Reymond P., Bruneton J. (1999). Les composes phénoliques. In : pharmacognosie, phytochimie, plantes médicinales, $3^{\mathrm{e}}$ édition, éd. TEC et DOC, Paris, France 225-460.

7. Couderchet M., Le Floch G., Rey P., Tirilly Y. (2003). Effet du flumioxazine sur l'attaque de feuilles de tomate par Botrytis cinerea. In AFPP, édition: $7^{\text {ème }}$ Conférence internationale sur les maladies des plantes, Tours, France.

8. Coulibaly A. (2014). Situation actuelle et défis de la filière coton ivoirienne. Communication de la Côte d'Ivoire à la $73^{\text {ème }}$ plénière du Comité Consultatif International du Coton $(\mathrm{CCIC})$, Thessalonique, Grèce. pp. 5.

9. $\quad$ Delattre R. (1973). Parasites et maladies en culture cotonnière. IRCT, Paris. pp. 146.

10. Djapic N. (2012). Chlorophyll catabolism in Prunus serrulata autumnal leaves. Facta Universitatis Series: Physics, Chemistry and Technology10 (1): 21 - 26

11. Djerbi M. (1990). Caracterization of Fusarium oxysporum f.sp. albedinis the causal agent of bayoud disease on the basis of vegetative compatibility. Procceding of eight congress of the Meriterranean Phytopathological union, Agadir, Morocco. pp. 513.

12. Ellis G.H., Matrone G., Maynard LA. (1946). A 72 per cent sulfuric acid method for the determination of lignin and its use in animal nutrition. Journal.Animal.Sciences, 5: 285-297.

13. Estur. (2005). Rôle possible des phénols liés aux parois et des feniloyl et $p$-coumaroyl oxydase dont l'embryogenèse somatique du palmier dattier. Second International Electronic Conference On Synthetic Organic Chemistry (Ec Soc - 2) Sept. 1 - 30.

14. Faurie B., Cluzert S., Corio-Costet MF., Mérillon J.M. (2013). Methyl jasmonate/ethephon cotreatment synergistically induce stilbene production in Vitis vinifera cell suspensions but fails to trigger resistance to Erysiphe necator. Journal Interface Sciences. Vigne Vin 43(2) : 99-110.

15. Folly P. (2000). Catabolisme de la chlorophylle b Structures, mécanismes et synthèses. Thèse de doctorat de l'Université de Fribourg, Suisse. pp.192.

16. Hau B., Goebel S. (1987). Modifications du comportement du cotonnier en fonction de l'environnement : 1. Evolution des paramètres de productivité de neuf variétés semées à trois écartements. Coton et Fibres Tropicales 105 (2): 165-173.

17. Henni J.E., Fortas Z., Geiger JP. (1998). Etude de la compatibilité végétative chez des souches de Fusarium oxysporum isolées dans la région ouest de l'Algérie. Phytopathologia Medititerranea 37: 69-74.

18. Koffi KK., Anzara GK., Malice M., Djè Y., Baudoin JP., Bi IZ. (2009). Morphological and allozyme variation in a collection of Lagenaria siceraria (Molina) Standl. From Côte d'Ivoire 13: 257-270.

19. Konan YKF., Kouassi KM., Kouakou KL., Koffi E., Kouassi K.N., Sékou D., Koné M., Kouakou TH. (2014). Effect of Methyl jasmonate on phytoalexins biosynthesis and induced disease resistance to Fusarium oxysporum f. sp. vasinfectum in Cotton (Gossypium hirsutum L.). International Journal of Agronomy 1-11.

20. Konan Y.K.F. (2015). Stimulation des défenses naturelles du cotonnier (Gossypium hirsutum L., Malvaceae) par le méthyle jasmonate et l'éthéphon : Effet sur la biosynthèse des composés phénoliques et sur la résistance à Fusarium oxysporum f. sp. Vasinfectum, agent causal de la fusariose. Thèse de doctorat. Université Nangui Abrogoua, Abidjan, Côte d'Ivoire. pp. 207. 
21. Letellier M., Fleurent D.V. (2012). Caractérisation chimique, physique et mécanique de Pieux Anciens. Projet de fin d'études Ingénieur 3ème année. Université Lorraine. pp.127.

22. Lichtenthaler H.K., Buschmann C. (2001). Chlorophylls and carotenoids: measurement and characterization by UV-VIS. In: Wrolsta R.E., Acree T.E., Decker E.A., Penner M.H., Reid D.S., Schwartz, S.J., Shoemaker C.F., Sporns P. Current protocols in food analytical chemistry 431-438.

23. Lyon GD., Reglinski T., Newton A.C. (1995). Novel disease control compounds: the potential to immunize plants against infection. Plant Patholology 44 : 407-427.

24. Morot-Gaudry J.F., Farineau. J. (2011). La Photosynthese: processus Physiques, Moléculaires et Physiologiques. Paris, France. pp. 403.

25. Munro J..M. (1994). Cotton longman Scientific and Technical, England. pp. 436.

26. N'cho. (2018). Élicitation du bananier par le méthyle jasmonate et l'acide salicylique : impact sur les composés phénoliques, efficacité sur Mycosphaerella fijiensis responsable de la maladie des raies noires.

27. Olson J.M. (2006). Photosynthesis in the Archean Era. Photosynthesis Research, 88 (2): 109-117.

28. Perraud A. (1971). La matière organique des sols de la Côte d'Ivoire (Relations sols-végétation-climat). Thèse Nancy. pp. 87.

29. SODEXAM. (2017). Données météorologiques de 2006-2016 d'Abidjan. Société d'exploitatation et de développement Aéroportuaire, aéronautique et Météorologiques : direction de la Météorologie Nationale, Port-Bouët-Abidjan (Côte d'Ivoire).

30. Stassiaux J. (2010). Prégnénolone et chlorophylle. http://www.naturopathie-holistique.fr/pregnenoloneet-chlorophylle-15-127. Accessed April 17, 2014.

31. Raven H., Evert R.F., Eichhorn SE. (2007). Physiologie Végétale 2ème édition, coll. « Editions De Boeck Université », Bruxelles, Belgique. pp.121.

32. Vaissayre M. (1994). Dix années d'expérimentation pour la protection du cotonnier en Côte d'Ivoire (19811990). Doc. CIRAD/CA 3(93): 1-57. 